\title{
Impact of Excess Body Weight on Postsurgical Complications
}

\author{
Lars Plassmeier Mohammed K. Hankir Florian Seyfried \\ Department of General, Visceral, Transplantation, Vascular, and Pediatric Surgery, University Hospital, Wuerzburg, \\ Germany
}

\section{Keywords}

Obesity · Surgical complications · Laparoscopy

\begin{abstract}
Background: Obesity is considered a risk factor for postoperative complications as it can limit exposure to the operation field, thereby significantly prolonging surgery time. Obesity-associated comorbidities, such as low-grade systemic inflammation, impaired functional status, and type 2 diabetes, are independent risk factors for impaired anastomotic wound healing and nonsurgical site infections. If obesity itself is an independent risk factor for surgical complications remains controversial, but the reason for this is largely unexplored. Summary: A MEDLINE literature search was performed using the terms: "obesity," "excess body weight," and "surgical complications." Out of 65,493 articles 432 meta-analyses were screened, of which 25 meta-analyses were on the subject. The vast majority of complex oncologic procedures in the field of visceral surgery have shown higher complication rates in obese patients. Meta-analyses from the last 10 to 15 years with high numbers of patients enrolled consistently have shown longer operation times, higher blood loss, longer hospital stay for colorectal procedures, oncologic upper gastrointestinal (Gl) procedures, and pancreatic surgery. Interestingly, these negative effects seem not to affect the overall survival in oncologic patients, especially in esophageal resections. A selection bias in oncologic upper Gl patients may have influenced the results with higher BMI in upper Gl cancer to be a predictor for better nutritional and performance status. Key Messages: Contrary to bariatric surgery, only limited evidence indicated that site
\end{abstract}

and type of surgery, the approach to the abdominal cavity (laparoscopic vs. open), institutional factors, and the type of perioperative care such as ERAS protocols may play a role in determining postsurgical complications in obese patients. The initial question remains therefore partially unanswered. Large nationwide register-based studies are necessary to better understand which aspects of obesity and its related comorbidities define it as a risk factor for surgical complications.

(C) 2021 The Author(s) Published by S. Karger AG, Basel

\section{Introduction}

Obesity has reached pandemic proportions, with an estimated prevalence of $34 \%$ in the USA and over $20 \%$ in Europe, while it exceeds $40 \%$ in some Middle Eastern countries [1]. Obesity can lead to impaired functional status and quality of life [2]. Moreover, obesity-associated comorbidities including type 2 diabetes, hypertension, cardiovascular diseases, and certain cancers reduce life expectancy [3].

Beyond its detrimental effects to health, there is evidence to suggest that obesity negatively impacts postsurgical outcomes. For example, excess adiposity limits exposure to the operation field, thereby significantly prolonging surgery times [4]. The chronic, low-grade systemic inflammation and impaired functional status associated with obesity may compromise postoperative recovery [5]. Obesity-associated comorbidities, such as hyperglycemia, are independent risk factors for impaired anastomotic wound healing and nonsurgical site infec-

(C) 2021 The Author(s)

Published by S. Karger AG, Basel

This is an Open Access article licensed under the Creative Commons Attribution-NonCommercial-4.0 International License (CC BY-NC) (http://www.karger.com/Services/OpenAccessLicense), applicable to the online version of the article only. Usage and distribution for commercial purposes requires written permission. 


\begin{tabular}{|c|c|c|}
\hline Electronic selection & \multicolumn{2}{|c|}{ Manual selection } \\
\hline $\begin{array}{l}\text { Pubmed search limitation based } \\
\text { on key words }\end{array}$ & $\begin{array}{l}\text { Abstract based exclusion } \\
\text { criteria }\end{array}$ & $\begin{array}{l}\text { Article based exclusion } \\
\text { criteria }\end{array}$ \\
\hline $\begin{array}{l}\text { - "obesity" } \\
\text { - "excess body weight" } \\
\text { - "diabetes" } \\
\text { - "surgical complications" } \\
\text { - "laparoscopic surgery" } \\
\text { - "bariatric surgery" } \\
\text { - "surgical outcome" }\end{array}$ & $\begin{array}{l}\text { - missing abstract } \\
\text { - case reports } \\
\text { - editorials } \\
\text { - commentaries } \\
\text { - articles not in English } \\
\text { - not surgery related }\end{array}$ & $\begin{array}{l}\text { - no data on surgical } \\
\text { outcomes } \\
\text { - small study population } \\
\text { - insufficient study quality }\end{array}$ \\
\hline
\end{tabular}

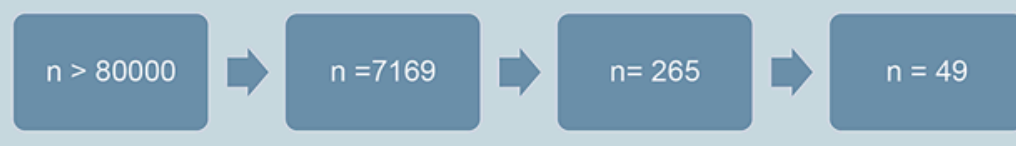

Fig. 1. Literature search process.

tions [6]. Obesity also increases the risk of developing thromboembolisms [7].

On the other hand, a large Swiss prospective cohort study concluded that excess BMI is not a risk factor for postsurgical complications [8]. Two major limitations are associated with this landmark study, however. First, the heterogeneity of patients diagnosed with obesity based on $\mathrm{BMI}$ alone is high and more sophisticated scaling systems such as the Edmonton obesity scoring system (EOSS) may more accurately reflect perioperative risk [9]. Second, apart from patient-related factors, the heterogeneity of surgical procedures and complications in the field of visceral surgery make it unlikely for excess body weight to be a universal risk factor. The site and type of surgery [10], the approach to the abdominal cavity (laparoscopic vs. open) [11], institutional factors such as individual surgical training and expertise [12], the type of perioperative care such as fast-track concepts [13], or the enhanced recovery after surgery (ERAS) protocol may all play an important role [14] in determining postsurgical complications. The purpose of this review therefore is to address the impact of excess weight and possible patient-, surgery-, and institutional-related factors on surgical outcomes.

\section{Methods}

To identify studies on postsurgical complications in abdominal surgery, we performed a MEDLINE literature search using the terms: "obesity," "excess body weight," and "surgical complications." We focused on meta-analyses and could identify 432 out of the 65,493 articles. All 432 meta-analyses were screened based on their abstracts. The vast majority of these were on the subject bariatric surgery, which was not the focus of this review. This left
25 meta-analyses (Fig. 1), which were systematically analyzed (Table 1). We extended our research based on our hypotheses that the site and type of surgery, the approach to the abdominal cavity (laparoscopic vs. open), institutional factors such as individual surgical training and expertise, the type of perioperative care such as fast-track concepts, or the ERAS protocol may all play an important role in determining postsurgical complications in a nonsystematic manner.

\section{Obesity-Associated Comorbidities Affecting Postoperative Outcomes}

\section{Impaired Functional Status and Postoperative \\ Recovery}

Obesity is usually associated with impaired functional status and is therefore believed to affect, or at least delay, postoperative recovery [5], but current evidence in support of this is conflicting $[5,8,15]$. For instance, BMI alone was not associated with any postoperative complication or delayed recovery in a study on the effect of visceral obesity or sarcobesity in laparoscopic resections for colorectal cancer [16]. In contrast, excess body weight has been shown to impair postoperative results in colorectal cancer resection [5]. A recent development for improving postoperative recovery is ERAS. This comprises a professionally guided program on quicker mobilization and more effective physiotherapy with the primary goal of reducing length of stay (LOS) and optimizing cost-effectiveness. This program has been shown to reduce LOS in bariatric surgery patients as well as postoperative complications [17], thereby emphasizing the importance of optimized strategies for the postoperative treatment of obese patients. 
Table 1. Cited studies

\begin{tabular}{|c|c|c|c|c|c|c|c|}
\hline Author & Year & Timespan & $\begin{array}{l}\text { Individuals } \\
\text { included }(n)\end{array}$ & Topic & Studies included & $\begin{array}{l}\text { Primary } \\
\text { endpoint }\end{array}$ & Comment \\
\hline Hong et al. [79] & 2013 & 1960-2012 & 1,988 & $\begin{array}{l}\text { Excess body weight in } \\
\text { esophageal carcinoma }\end{array}$ & 6 (retrospective) & Survival & $\begin{array}{l}\text { Trends obese in poorer OS, } \\
\text { higher complication rates, } \\
\text { older data }\end{array}$ \\
\hline Zhou et al. [4] & 2012 & $2002-2009$ & $>2,000$ & $\begin{array}{l}\text { Laparoscopic resection } \\
\text { CRC in obese }\end{array}$ & 8 (all observational) & Complications & $\begin{array}{l}\text { Higher SSI rates, similar } \\
\text { oncologic outcome }\end{array}$ \\
\hline Woodham et al. [62] & 2012 & $2001-2008$ & 2,428 & $\begin{array}{l}\text { Laparoscopic versus open } \\
\text { appendectomy in obese }\end{array}$ & $\begin{array}{l}7 \text { ( } 2 \text { RCTs, } 1 \\
\text { prospective cohort } \\
\text { study, } 4 \text { retrospective) }\end{array}$ & $\begin{array}{l}\text { Postoperative } \\
\text { outcome }\end{array}$ & $\begin{array}{l}\text { All-obese collective, study } \\
\text { favors lap. appendectomy }\end{array}$ \\
\hline McIntiyre et al. [54] & 2020 & $2013-2018$ & $>1.5$ mio & $\mathrm{LC}$ & 44 & Readmission & $\begin{array}{l}\text { Extremely large cohort, } \\
\text { obesity was not the main } \\
\text { topic }\end{array}$ \\
\hline Fung et al. [80] & 2016 & -2014 & 4,550 & $\begin{array}{l}\text { Laparoscopic colorectal } \\
\text { cancer resection (obese vs. } \\
\text { nonobese) }\end{array}$ & $\begin{array}{l}13 \text { ( } 3 \text { retrospective, } \\
10 \text { prospective) }\end{array}$ & $\begin{array}{l}\text { Oncologic } \\
\text { outcome }\end{array}$ & $\begin{array}{l}\text { No difference in oncologic } \\
\text { outcome }\end{array}$ \\
\hline Sun et al. [52] & 2020 & 1994-2014 & 9,572 & $\begin{array}{l}\text { Laparoscopic gastrectomy } \\
\text { obese versus nonobese }\end{array}$ & 15 (all retrospective) & $\begin{array}{l}\text { Surgical } \\
\text { outcome }\end{array}$ & $\begin{array}{l}\text { Only Asian collective, BMI } \\
\text { cutoff only } 25\end{array}$ \\
\hline $\begin{array}{l}\text { Shabanzadeh et al. } \\
\text { [11] }\end{array}$ & 2012 & $1992-2011$ & 58,755 & SSI in obese (lap. vs. open) & $\begin{array}{l}44 \text { (8 RCTs, } 36 \\
\text { observational) }\end{array}$ & SSI & $\begin{array}{l}\text { Large collective with high } \\
\text { fraction of bariatric surgeries }\end{array}$ \\
\hline Saab et al. [59] & 2013 & 1993-2013 & 76,620 & $\begin{array}{l}\text { Liver transplant recipients } \\
\text { (obese vs. nonobese) }\end{array}$ & 13 (retrospective) & Survival & $\begin{array}{l}\text { Large but heterogeneous } \\
\text { collective }\end{array}$ \\
\hline Danwang et al. [64] & 2020 & 2000-2019 & 1,381 & $\begin{array}{l}\text { Laparoscopic } \\
\text { adrenalectomy in obese }\end{array}$ & $\begin{array}{l}5 \text { (1 prospective, } \\
3 \text { retrospective, } \\
1 \text { unclear) }\end{array}$ & $\begin{array}{l}\text { Postoperative } \\
\text { outcome }\end{array}$ & $\begin{array}{l}\text { Small sample size in meta- } \\
\text { analysis for many aspects }\end{array}$ \\
\hline Makino et al. [66] & 2012 & $1983-2010$ & 9,231 & $\begin{array}{l}\text { Laparoscopic colorectal } \\
\text { resection (obese vs. } \\
\text { nonobese) }\end{array}$ & 33 (all retrospective) & $\begin{array}{l}\text { Postoperative } \\
\text { outcome }\end{array}$ & $\begin{array}{l}\text { Large sample size, all } \\
\text { retrospective data }\end{array}$ \\
\hline Kayani et al. [48] & 2012 & $1977-2008$ & 1,682 & $\begin{array}{l}\text { Esophagectomy (obese vs. } \\
\text { nonobese) }\end{array}$ & 5 (all retrospective) & OS, M\&M & $\begin{array}{l}\text { Partly old data, limited } \\
\text { information about } \\
\text { characteristics of obesity }\end{array}$ \\
\hline Mengardo et al. [47] & 2017 & $1977-2011$ & 2,838 & $\begin{array}{l}\text { Esophagectomy (obese vs. } \\
\text { nonobese) }\end{array}$ & $\begin{array}{l}8 \text { ( } 4 \text { prospective, } \\
4 \text { retrospective) }\end{array}$ & OS, M\&M & $\begin{array}{l}\text { Inconsistent definition of } \\
\text { obesity }\end{array}$ \\
\hline Wee et al. [45] & 2019 & $2016-2018$ & 1,024 & $\begin{array}{l}\text { Robotic and laparoscopic } \\
\text { colorectal surgery in obese }\end{array}$ & 9 (retrospective) & $\begin{array}{l}\text { Surgical } \\
\text { outcomes }\end{array}$ & $\begin{array}{l}\text { Effect of learning curve in } \\
\text { robotic resections unclear, } \\
\text { higher conversion rates in } \\
\text { obese }\end{array}$ \\
\hline $\begin{array}{l}\text { Abdelraman et al. } \\
\text { [53] }\end{array}$ & 2018 & $2001-2017$ & 7,999 & $\begin{array}{l}\text { Antireflux surgery } \\
\text { outcomes related to } \\
\text { obesity }\end{array}$ & $\begin{array}{l}13 \text { ( } 6 \text { retrospective, } \\
7 \text { prospective cohort } \\
\text { studies) }\end{array}$ & $\begin{array}{l}\text { GERD } \\
\text { recurrence, } \\
\text { complications }\end{array}$ & $\begin{array}{l}\text { Heterogeneous collective, } \\
\text { different techniques; higher } \\
\text { rate of reflux relapse in obese }\end{array}$ \\
\hline Bell et al. [42] & 2019 & $1990-2017$ & 6,779 & $\begin{array}{l}\text { Oncologic safety lap } \\
\text { versus open CRC surgery } \\
\text { in obese }\end{array}$ & $\begin{array}{l}20 \text { (4 prospective, } \\
16 \text { retrospective) }\end{array}$ & $\begin{array}{l}\text { OS, DFS, } \\
\text { surgical } \\
\text { outcomes }\end{array}$ & $\begin{array}{l}\text { Higher conversion rates in } \\
\text { non-Asian collective, higher } \\
\text { R1-resection in obese }\end{array}$ \\
\hline Hussan et al. [5] & 2016 & 2012 & 85,000 & $\begin{array}{l}\text { Outcomes morbidly obese } \\
\text { in CRC resections }\end{array}$ & No meta-analysis & $\mathrm{M} \& \mathrm{M}$ & $\begin{array}{l}\text { Only study regarding BMI } \\
>40 \text {, significant increase in } \\
\text { all complications }\end{array}$ \\
\hline
\end{tabular}

LC, laparoscopic cholecystectomy.

\section{Diabetes}

Type 2 diabetes mellitus is one of the most frequent obesity-associated comorbidities with an incidence of approximately $20-40 \%$ [16]. It is also a major risk factor for surgical complications in a wide variety of surgical proce- dures [18]. In 1 study, HbAlc levels above $8.0 \%$ significantly increased the odds ratio for surgical site infections [6]. A recent study from Japan showed an $\mathrm{HbA1c}$-associated increase in anastomotic leakage, SSIs, and even postoperative pneumonia in patients undergoing esophagec- 
tomy [19]. A meta-analysis of over 600,000 patients undergoing colorectal surgery found significantly higher rates of SSIs, anastomotic leaks, urinary tract infections, and hospital readmissions in the group with type 2 diabetes [20]. Some studies identified type 2 diabetes to be a trigger for other cardiovascular complications if it was at an advanced stage with end-organ diseases or other comorbidities [21].

\section{Obstructive Sleep Apnea}

Obstructive sleep apnea (OSA) is a common comorbidity in obese patients [22]. Studies have shown that around $70 \%$ of OSA patients are overweight or obese and the weight loss reduces OSA symptoms [23]. Unsurprisingly, OSA is strongly affected by anesthesia and leads to a variety of postoperative complications, especially pulmonary complications such as pneumonia, but also cardiac events [24]. A key factor is preoperative screening and treatment of OSA prior to surgery, which improves postoperative outcomes [25]. As OSA is associated with other comorbidities, the independent impact of OSA on postoperative outcomes is hard to define. Studies show differing results on whether OSA is a sole risk factor for postoperative complications [23]. OSA patients suffer from chronic pain, which increases analgesic use (especially opioids) and further worsens respiratory impairment [26]. Anesthesiologic management of these patients is complex and is still the subject of active discussion. Optimizing OSA impairment in the preoperative phase helps to reduce postoperative complications [25].

\section{Chronic Obstructive Pulmonary Disease}

Chronic obstructive pulmonary disease (COPD) is a well-known comorbidity of obesity, but it is also a significant risk factor for numerous severe postoperative complications [27]. In abdominal surgery, COPD, smoking, and obesity were found to be independent risk factors for reoperation and hospital readmission in ventral hernia repair patients [28]. In an Australian retrospective study, COPD and atrial fibrillation were independent risk factors for postoperative complications in colorectal surgery, but not increased BMI alone [19]. Postoperative pneumonia is a typical nonsurgical site infection. Its perioperative risk includes patient-related, surgery-related, and institutional factors. A prospective study from Jordan has shown that through implementation of an optimized postoperative pulmonary care, obesity could be ruled out as a risk factor for the development of postoperative pneumonia in over 1,600 patients undergoing gastrointestinal (GI) cancer resections [29].

However, obesity was identified as a risk factor for developing pneumonia in abdominal trauma patients undergoing emergency surgery in a large register study with over 95,000 cases [30]. Here, up to $15 \%$ of obese patients developed postoperative pneumonia. These data are in line with a study from Mathur et al. [31] who investigated the influence of obesity in hepatectomy for malignancies where obese patients were 4 times more likely to suffer from postoperative pneumonia. Contrastingly, postoperative pneumonia is extremely rare in bariatric surgery. Even in large register studies, it occurred in $<1 \%$ of cases [32].

\section{Liver Disease}

The rising incidence of nonalcoholic fatty liver disease (NAFLD) is largely due to its close association with obesity [33]. It was shown to be a major cause of higher inhospital mortality rates and longer LOS in a retrospective study of over 7,000 patients undergoing colorectal surgery [34].

Notwithstanding the above, bariatric surgery is a safe option for the vast majority of NAFLD patients with low morbidity and complication rates shown in many studies [35]. Indeed, it mitigates and even cures NAFLD in about $85 \%$ of obese patients [36]. Preconditioning with highprotein formula diet prior to bariatric surgery not only improves metabolic status [37] but also improves the procedure's feasibility through liver shrinkage [38].

Liver cirrhosis has an even greater impact on postoperative complications. In a German single-center study with 138 cases undergoing abdominal surgery suffering from liver cirrhosis, overall mortality was $28 \%$, increasing in proportion to Child and MELD scores [39]. Child C patients had an in-hospital mortality of $63 \%$. These data underline the major impact of liver dysfunction on postoperative complications.

\section{Alternative Evaluation of Obesity}

Taking all of the issues discussed in this article into consideration, more complex scaling systems incorporating excess body weight with its possible functional and health consequences such as the EOSS may more accurately reflect perioperative risk [9]. The EOSS provides a more detailed approach to classifying obesity by its metabolic, cardiovascular, pulmonary, psychological, and orthopedic consequences. It provides a scoring system ranging from stage 0 to 4 in which 0 represents a noncompromised patient and 4 represents a severely compromised or end-stage comorbid obese patient. The EOSS has further been shown to accurately stratify mortality risk [40].

The EOSS has also been used as an assessment tool for predicting complications in bariatric surgery and showed validity for increased complications in EOSS 3 patients [41]. With this system, a classification method has been developed, which distinguishes patients of similar BMIs but has varying performance abilities and may thus provide a more detailed analysis of potential risk factors. To 
date, this tool has not been used for risk stratification apart from with bariatric surgery. Therefore, its broader surgical significance is yet to be demonstrated and requires future studies.

\section{Surgical Field and Postoperative Outcomes}

\section{Colorectal Surgery}

A meta-analysis by Hussan et al. [5] found morbid obesity (BMI $>40 \mathrm{~kg} / \mathrm{m}^{2}$ ) to be a risk factor for longer operation times, higher anastomotic leakage rates, and prolonged hospital stay, as well as higher overall treatment costs. Other meta-analyses focusing on surgical outcomes in patients diagnosed with Grade I and/or Grade II obesity found conflicting results.

Bell et al. [42] focused on the oncological outcome of obese patients undergoing colorectal surgery. They found obesity to be a predictor for slightly higher tumor-positive resection margins (R1) with $6.9 \%$ in the obese versus $3.1 \%$ in the nonobese group. Interestingly, obesity was not shown to be a risk factor for overall survival in this study. One study by Yang et al. [43] analyzed 4 studies describing the amount of visceral adiposity as a more specific factor. The authors also found visceral obesity to be associated with higher complication rates as well as prolonged operation times and lower lymph nodes harvested. However, the studies included were retrospective and derived from Asian populations with overall low BMIs.

Higher BMI leads to higher conversion rates in laparoscopic sigmoidectomy with correspondingly longer hospital stays and more postoperative complications. Notably, complication rates were even higher in converted cases than in primary open surgeries [44]. Interestingly, robotic surgery seems to improve the positive effects of the minimally invasive approach in laparoscopic colorectal surgery, reducing LOS and postoperative complications in a meta-analysis from Wee et al. [45] on robotic colorectal cancer resections compared with laparoscopic resections in the subgroup of obese patients with $262 \mathrm{pa}-$ tients enrolled. However, obese patients still had higher complication rates undergoing robotic surgery compared with their nonobese counterparts.

In contrast to the above, colorectal surgery studies have yet to show superiority for the laparoscopic approach in oncological disease. While for many of these studies oncological outcomes were defined as primary endpoints, nearly all showed that postoperative complications were similar for open versus laparoscopic surgery not regarding obesity [46].

\section{Upper Gastrointestinal Surgery}

There is a wide range of different upper GI procedures ranging from laparoscopic functional surgery such as an- tireflux surgery to complex oncological procedures requiring transabdominal and thoracic access such as esophagectomy. A meta-analysis by Mengardo et al. [47] including over 2,800 patients undergoing esophagectomy or transhiatal gastrectomy for adeno-, and squamouscell-carcinoma identified obesity as an individual risk factor for anastomotic leakage increasing the incidence by up to $35 \%$. The cutoff was set at BMI $>30 \mathrm{~kg} / \mathrm{m}^{2}$ and in some studies included at $>25 \mathrm{~kg} / \mathrm{m}^{2}$, so a qualified statement on the outcome of obese patients cannot be made. In contrast, another meta-analysis by Kayani et al. [48] could not find any negative effect of obesity on complications after esophagectomy but described better overall survival rates for overweight and obese patients. Lower BMI in upper GI cancer patients is assumingly associated with malnutrition and, therefore, poor performance status.

Overall, the vast majority of studies included dated back to the late 1980s, which may compromise its adaptability according to today's standards. However, the authors showed that obesity had no effect on R0-resection rate, mortality, respiratory failure, and reoperations, while a trend toward more anastomotic leakages and pulmonary embolisms was seen.

Due to these older data, some recent studies show promise on the effect of robotic-assisted Ivor-Lewis esophagectomy. Work by Salem et al. [49] could show that the operation time is longer in obese patients, but blood loss, postoperative pneumonia, anastomotic leakage, and SSIs as well as a 30-day mortality did not differ subject to obesity. A limitation of this study is that it comes from a specialized tertiary center performing 129 robotic esophagectomies from between 2010 and 2013, which seems not to set the general standard. Accordingly, a retrospective cohort analysis from 2020 by Sachdeva et al. [50] found that obese patients significantly more often undergo open esophagectomy compared to normalweight patients. In over 8,500 observed cases, conversion rates were higher in the morbidly obese group with an OR of 3.75. Similar to older meta-analyses 48 , this study finds similar oncologic outcomes but states significantly less neoadjuvant chemotherapy in uT2 uN0 stages in the obese group.

These findings are supported by a database analysis from Mitzman et al. [51] from 2018 with over 9,000 resections for esophageal cancer, of which $23 \%$ were open transhiatal, $33 \%$ open Ivor-Lewis, and 22\% minimally invasive Ivor-Lewis operations. Again underweight patients had increased risk for complications and mortality as well as BMI $>40 \mathrm{~kg} / \mathrm{m}^{2}$ patients. This very large and well worked-up retrospective analysis supports the old data for underweight as a poor performance marker.

A meta-analysis by Sun et al. [52] analyzing 15 retrospective studies from 1994 to 2014 reported the outcome 
of over 9,000 gastric cancer patients. They demonstrated that a BMI $>25 \mathrm{~kg} / \mathrm{m}^{2}$ is a risk factor for higher blood loss, longer operating time, fewer harvested lymph nodes, and higher rates of wound infections and postoperative ileus, but not for anastomotic leakage, bleeding, and overall postoperative recovery. This study only focused on laparoscopic gastrectomies and not on open surgery. It has to be acknowledged that all identified meta-analyses on this topic mainly included retrospective cohort studies and that the BMI cutoff value considerably varied between studies. Overall, moderately higher BMI (around $30 \mathrm{~kg}$ / $\mathrm{m}^{2}$ ) seems not to have a measurable impact on perioperative outcomes.

A meta-analysis by Abdelrahman et al. [53] including 13 studies, of which 7 were prospective cohort studies and enrolled over 5,000 patients, found obesity not to be a risk factor for complications in laparoscopic hiatal hernia repair with no impact on operation time, complications, or redo-surgery. Again no randomized trial was included and the studies varied in regarding length of follow-up and surgical techniques. However, the rates of reflux recurrence and recurrent hiatal hernia were increased [53], ranging between 0 and $10 \%$ in nonobese and $2-27 \%$ obese patients.

\section{Hepatobiliary and Pancreatic Surgery}

Procedures in the field of hepatobiliary and pancreatic surgery vary from laparoscopic cholecystectomy (LC) to much more complex surgeries like pancreatoduodenectomy or liver transplantation. As this large surgical field is beyond the scope of this review, we focused on some of the most frequently performed procedures.

\section{Laparoscopic Cholecystectomy}

A large meta-analysis by McIntyre et al. [54] with over $1,500,000$ million patients from 44 studies showed no impact of obesity on readmission after discharge from LC. Other data on complications related to obesity are not shown in this study. The main strength of this study is the large sample size, however since only LCs were included; there are no data on open surgery. A retrospective cohort study from Japan found no impact of obesity on complications after LC in 563 patients with an overall complication rate of $1.2 \%$. In this study, BMI cutoff was set at 25 $\mathrm{kg} / \mathrm{m}^{2}$ and median BMI in the obese group was $28.1 \mathrm{~kg} /$ $\mathrm{m}^{2}$, as the standard was adjusted for Asian collectives [55]. Known risk factors for complications after cholecystectomy are increased operative time, worsening leukocytosis, and jaundice, whereas risk factors for a 30-day readmission were prior biliary complication, male sex, and operative duration in a prospective multicenter study from the USA including 989 patients [56]. Obesity is over multiple studies no risk factor for postoperative complications.

\section{Pancreatic Surgery}

The impact of obesity on development of postsurgical complications in pancreatic surgery was investigated by Shamali et al. [57] in a cohort study including 524 patients undergoing pancreatoduodenectomy, of which 18.5\% were obese. Obese patients suffered from higher intraoperative blood loss, longer operative time, higher rates of postoperative pancreatic fistula, and intraoperative collections. Obesity had no effect on overall survival. These findings could not be supported by a meta-analysis from Ramsey et al. [58]. Here, over 4,000 patients of which at least 592 had a BMI $>30 \mathrm{~kg} / \mathrm{m}^{2}$ from 17 retrospective studies undergoing pancreatic resections were included. BMI cutoffs were set different between 25 and $30 \mathrm{~kg} / \mathrm{m}^{2}$, so the definition of obese patients varied. Interestingly, the expected higher complication rates did not occur in obese patients regarding blood loss, operation time, number of harvested lymph nodes, and SSIs. However, the investigated studies in this meta-analysis widely differed, as complications rates varied between 10 and $50 \%$ in the obese groups. The authors similarly could prove an association between higher BMI and pancreatic fistula rates after pancreatic resections, but this did not lead to higher in-hospital mortality or decreased overall survival [58].

\section{Liver Transplantation}

In a large analysis on the outcomes of liver transplantation with over 70,000 patients from 13 studies, obesity was not a risk factor for poor survival, but in a subgroup pooled analysis, obese patients with the same cause of liver impairment than their nonobese counterparts had reduced survival compared to the nonobese [59]. However, comorbidities like hypertension and diabetes may be the reason for the poorer outcome in obese patients.

\section{Confounding Factors Affecting Postoperative Outcome}

\section{Elective versus Emergency Surgery}

Emergency surgery is often associated with higher complication rates than elective surgery; however, data for the impact of excess body weight are sparse. One recent retrospective study investigated the effect of obesity on postoperative outcomes in acute diverticulitis. This study showed a higher rate of reoperation and SSIs in obese patients, but no increased mortality or prolonged hospital stay [60].

\section{Open versus Laparoscopic Surgery}

In a prospective, single-center study including elective abdominal surgeries with over 6,000 patients enrolled, Dindo et al. [8] did not find obesity to be an independent risk factor for postoperative complications [15]. However, 
they described lower rates of SSIs for laparoscopic procedures, which have been confirmed by other studies [61]. A meta-analysis from Shabanzadeh et al. [11] with 44 studies included of which 8 were RCTs finds a risk reduction by $70-80 \%$ for SSIs in laparoscopic surgery compared to open surgery. Limiting here is the fact that only 1 RCT observed nonbariatric surgery. This effect was also demonstrated in a meta-analysis on appendectomies by Woodham et al. [62] in 2012 in obese patients showing a significant reduction of SSIs and hospital stay in the laparoscopic group, but again lack of strong evidence, as all included studies were non-RCTs and analyzed data were lacking even BMI of some individuals. Unfortunately, data reporting surgical outcomes on severely obese patients in a more general sense are missing. Therefore, robust evidence obtained from large prospective cohort studies from patients undergoing bariatric surgery may allow some more general conclusions. Those studies have shown a clear benefit of the laparoscopic over the open approach [63]. Overall, morbidities such as SSIs, incisional hernias, blood loss, and lower quality of life as well as mortality rates were significantly improved when the laparoscopic approach was used. Presently, according to evidence-based international guidelines, the laparoscopic approach is the standard in bariatric surgery. These data are supported by a meta-analysis by Danwang et al. [64] on outcomes of laparoscopic adrenalectomies, a procedure which is a well-established minimally invasive surgery showing no impact of obesity on postsurgical complications but also does only analyze the data from retrospective studies with an overall low number of patients included.

Data about laparoscopic colorectal surgery on complications comparing obese and nonobese were provided by Zhou et al. [4] in a meta-analysis from 2012, showing significantly higher rates of postoperative ileus, pulmonological complications, and SSIs, but not on anastomotic leakage, intra-abdominal abscess, or bleeding. Again, however, the analyzed studies were all retrospective cohort studies [4].

\section{Complexity of the Surgical Procedure}

It is widely assumed that complex surgical procedures tend to be even more difficult to perform in obese patients; however, the available evidence indicates otherwise. Excess weight was not identified as an independent risk factor for poor outcomes in laparoscopic left-sided colectomy in a collective with perforated diverticulitis [65]. Another single-center study reported even shorter hospital stays in obese patients after laparoscopic left-sided colectomy [66]. The same results were reported for robotic colorectal surgery. Conversion rates, blood loss, and operative times were not significantly higher in a retrospective single-center study from 2005 where 111 patients were examined. Only surgical site infections oc- curred more often in obese patients [67]. Overall, these data are provided by retrospective single-center studies assuming risk of selection bias as some specialized centers may achieve very good results even in complex surgical procedures despite obesity.

In addition to these results, complexity and skill may matter more in obese patients shown in a study by Birkmeyer et al. [12]. They assessed surgical skills and related it to the postoperative outcome. Lower skill levels resulted in significantly higher complication rates, higher mortality, and longer operative times, reoperation, and readmission [68]. This again suggests that skill and experience in the surgery of obese patients may significantly affect their feasibility and safety.

A recent study from Markar et al. [69] investigated outcomes in minimally invasive esophagectomies separating cohort from the TIME trial with 115 patients treated in highly specialized centers and under very selective study environments and the national database with 4,605 patients. Only the study population achieved lower complications and better outcomes in the minimally invasive group, whereas the database population fell short and suffered from higher complication rates in minimally invasive esophagectomies [69]. While this study did not focus on BMI or obesity, it shows the relevance of experience and skill in highly ambitious surgical approaches, which underlines the need of specialization and centralization of centers performing complex surgeries.

\section{Institutional Factors}

Quality assurance has been introduced to numerous fields in surgery. For example, the positive effect of specialization of surgical divisions is widely known and has led to improvement of quality and patients' security. This has been shown in colorectal surgery, pancreatic surgery, and many other procedures beyond surgery [8]. Also, personal skill specification and training improve surgical outcomes and reduce complications [12]. Unfortunately, these effects could not yet be demonstrated for obesity as an independent risk factor.

Bariatric surgery may serve to exemplify the benefits of standardization in treatment algorithms [8]. Thus far, evidence suggests that the treatment of bariatric patients in centers of excellence improves outcomes [70]. This is unsurprising since third-party certification ensures that necessary infrastructure and exact protocols for any given procedure and especially complication management are available [8]. Therefore, many studies prove that the quality of surgery alone is often not different in high volume centers compared to low volume centers [12]. The difference is made in the so-called failure to rescue. This term describes how good complication management works in measures of mortality by complications. Of course, this does not end with treatment algorithms and expertise in 
surgery, but extends to nearly all divisions of health care, from physical therapy, dietetics, nursing, and equipment, like heavy-duty operations and CT tables to management structures and so on.

\section{Anticoagulation and Thromboembolism}

Venous thromboembolisms can be a major cause of complications following surgery. In addition, pulmonary artery embolisms are potentially lethal. Obesity has been shown to be a risk factor for venous thromboembolisms in the long-term outcome after colorectal surgery [71]. Therefore, the prophylactic use of low-molecular weight heparin is recommended in such cases [72]. A meta-analysis investigating the effect of increased BMI on patients with esophageal cancer after esophagectomy in 5,480 patients showed significantly higher risk of thromboembolic complications in the obese group (OR 2.05) than normal weight [73]. In obese patients, the correct dosage is not well defined and international guidelines do not provide an evidence-based recommendation. A randomizedcontrolled trial by Steib et al. found no thromboembolisms in a gastric bypass cohort using $4,000,6,000$, or $2 \times$ 4,000 units of enoxaparine [74]. Application of 6,000 units once daily resulted in the highest rate of antifactor Xa activity. Therefore, this dosage could be suggested for obese patients without renal failure. Experts suggest even higher doses of LWMH in obese patients, but this is still under discussion [75].

\section{Comment}

While far from unanimous, most studies suggest that obesity is a risk factor for postoperative SSI $[15,67]$. Many studies though could show that minimally invasive techniques reduce SSIs overall and especially in colorectal procedures [44].

For the most common comorbidities such as diabetes, their impact on postsurgical complications is well documented $[6,18,19]$. Improving these comorbidities prior to (elective) surgery is a must whenever possible to achieve better outcomes [37].

An excellent example of successful surgical management, even in super-obese patients, comes from metabolic and bariatric surgery. In many studies, patient and procedure safety have been proven at a high level, even though comorbidities significantly increase the risk of surgical complications [76]. In this setting, the standardization and implementation of therapeutic pathways and successful development of laparoscopic procedures as well as the establishment of certified centers of excellence have made surgery safe and complication rates relatively low [12]. Despite complex settings, from anesthesia management and surgical feasibility to post- operative complication management, many studies show that the assignment to specialized hospitals improves outcomes and reduces complications [8], except for bariatric surgery where higher complication rates have been shown for seriously ill patients, that is, EOSS 3 and 4 [41].

The vast majority of open and/or complex oncologic procedures in the field of visceral surgery have shown higher complication rates in obese patients [4]. Metaanalyses from the last 10 to 15 years with high numbers of patients enrolled consistently have shown higher operation times, higher blood loss, longer hospital stay for colorectal procedures [42], oncologic upper GI procedures [47], and pancreatic surgery [58]. Interestingly, these negative effects seem not to affect the overall survival in oncologic patients, especially in esophageal resections. A selection bias in oncologic upper GI patients may have influenced the results with higher BMI in upper GI cancer to be a predictor for better nutritional and performance status.

In laparoscopic surgery, the (negative) effects of obesity seem to be less immanent compared to open surgeries. We assume that standardized laparoscopic procedures improve the outcome in obese patients when they are established widely based similar to bariatric surgery. During our research, we found the majority of studies in the field of bariatric surgery. Studies investigating the effect of laparoscopic versus open surgery in an obese but nonbariatric collective are vastly lacking. Many studies demonstrated evidence for functional superiority and oncologic equality or superiority of minimally invasive approaches in a wide range in the field of general and visceral surgery from hernia surgery to oncologic upper GI or colorectal surgery $[77,78]$. These studies focus on oncologic questions or technical feasibility, so understandingly obese patients are mainly excluded here. Therefore, the implications made by these studies are not one-to-one transferable to an obese collective. Especially randomized-controlled trials investigating the effect of obesity on surgical complications are missing. Additionally, studies that selectively investigate $\mathrm{BMI}>40 \mathrm{~kg} / \mathrm{m}^{2}$ patients, which are not bariatric surgery studies, are completely missing. Facing obesity increasing worldwide this aspect will become more and more significant in our daily routine and should be therefore investigated.

The initial question remains therefore partially unanswered and has to be specified as we have already learned that obesity alone is not always a good parameter in risk assessment. Large nationwide register-based studies are necessary to better understand which aspects of obesity and its related comorbidities define it as a risk factor for surgical complications. 


\section{Conflict of Interest Statement}

The authors declare no conflict of interest.

\section{Funding Sources}

The authors received no funding.

\section{Author Contributions}

L.P. performed the literature search, produced the figure, and wrote the manuscript. M.K.H. critically revised the manuscript. F.S. conceived and wrote the manuscript.

\section{References}

1 World Health Organisation: Global report on obesity 2014.

2 Grönroos S, Helmiö M, Juuti A, Tiusanen R, Hurme S, Löyttyniemi E, et al. Effect of laparoscopic sleeve gastrectomy versus Roux-en$\mathrm{Y}$ gastric bypass on weight loss and quality of life at 7 years in patients with morbid obesity: the sleevepass randomized clinical trial. JAMA Surg. 2020 Dec 9:e205666.

3 Deitel M. Overweight and obesity worldwide now estimated to involve 1.7 billion people. Obes Surg. 2003;13:329-30.

4 Zhou Y, Wu L, Li X, Wu X, Li B. Outcome of laparoscopic colorectal surgery in obese and nonobese patients: a meta-analysis. Surg Endosc. 2012;26:783-9.

5 Hussan H, Gray DM 2nd, Hinton A, Krishna SG, Conwell DL, Stanich PP. Morbid obesity is associated with increased mortality, surgical complications, and incremental health care utilization in the peri-operative period of colorectal cancer surgery. World J Surg. 2016 Apr;40(4):987-94.

6 Gabriel RA, Hylton DJ, Burton BN, H Schmidt $\mathrm{U}$, Waterman RS. The association of preoperative haemoglobin A1c with 30-day postoperative surgical site infection following noncardiac surgery. J Perioper Pract. 2019 Oct; 30(10):320-5.

7 Blokhin IO, Lentz SR. Mechanisms of thrombosis in obesity. Curr Opin Hematol. 2013 Sep;20(5):437-44.

8 Dindo D, Muller MK, Weber M, Clavien PA. Obesity in general elective surgery. Lancet. 2003;361:2032-5.

9 Bastawrous AL, Landmann RG, Liu Y, Liu E, Cleary RK. Incidence, associated risk factors, and impact of conversion to laparotomy in elective minimally invasive sigmoidectomy for diverticular disease. Surg Endosc. 2020 Feb;34(2):598-609.

10 Danwang C, Agbor VN, Bigna JJ. Obesity and postoperative outcomes of the patients with laparoscopic adrenalectomy: a systematic review and meta-analysis. BMC Surg. 2020;20:194

11 Shabanzadeh DM, Sørensen LT. Laparoscopic surgery compared with open surgery decreases surgical site infection in obese patients: a systematic review and meta-analysis. Ann Surg. 2012;256(6):934-45.

12 Birkmeyer JD, Finks JF, O'Reilly A, Oerline M, Carlin AM, Nunn AR, et al. Surgical skill and complication rates after bariatric surgery. N Engl J Med. 2013 Oct 10;369(15):1434-42.
13 Vlug MS, Wind J, Hollmann MW, Ubbink DT, Cense HA, Engel AF, et al. Laparoscopy in combination with fast track multimodal management is the best perioperative strategy in patients undergoing colonic surgery: a randomized clinical trial (LAFA-study). Ann Surg. 2011;254:868-75.

14 Varadhan KK, Neal KR, Dejong CH, Fearon KC, Ljungqvist O, Lobo DN. The enhanced recovery after surgery (ERAS) pathway for patients undergoing major elective open colorectal surgery: a meta-analysis of randomized controlled trials. Clin Nutr. 2010;29:434.

15 Pedrazzani C, Conti C, Zamboni GA, Chincarini $M$, Turri $G$, Valdegamberi A, et al. Impact of visceral obesity and sarcobesity on surgical outcomes and recovery after laparoscopic resection for colorectal cancer. Clin Nutr. 2020 Dec;39(12):3763-70

16 Mokdad AH, Ford ES, Bowman BA, Dietz WH, Vinicor F, Bales VS, et al. Prevalence of obesity, diabetes, and obesity-related health risk factors, 2001. JAMA. 2003;289:76-9.

17 Mannaerts GHH, Allatif REA, Al Hashmi FY, Bhosale A, Hammo AN, Isied SH, et al. First successful large-scale introduction of an enhanced recovery after bariatric surgery (ERABS) program in the Middle East: the results and lessons learned of tawam hospital/ Johns hopkins, a tertiary governmental center in the UAE. Obes Surg. 2019 Jul;29(7):2100-9.

18 Bamba R, Gupta V, Shack RB, Grotting JC, Higdon KK. Evaluation of diabetes mellitus as a risk factor for major complications in patients undergoing aesthetic surgery. Aesthet Surg J. 2016 May;36(5):598-608.

19 Okamura A, Yamamoto H, Watanabe M, Miyata H, Kanaji S, Kamiya K, et al. Association between preoperative HbA1c levels and complications after esophagectomy: analysis of 15,801 esophagectomies from the national clinical database in Japan. Ann Surg. 2020 Nov 17.

20 Tan DJH, Yaow CYL, Mok HT, Ng CH, Tai $\mathrm{CH}$, Tham HY, et al. The influence of diabetes on postoperative complications following colorectal surgery. Tech Coloproctol. 2021 Jan 1;25(3):267-78.

21 Wei C, Kapani N, Quan T, Gu A, Fassihi SC, Malahias MA, et al. Diabetes mellitus effect on rates of perioperative complications after operative treatment of distal radius fractures. Eur J Orthop Surg Traumatol. 2021 Jan 25.

22 Romero-Corral A, Caples SM, Lopez-Jimenez F, Somers VK. Interactions between obesity and obstructive sleep apnea: implications for treatment. Chest. 2010;137:711-9.
23 Peppard PE, Young T, Palta M, Dempsey J, Skatrud J. Longitudinal study of moderate weight change and sleep-disordered breathing. JAMA. 2000;284:3015-21.

24 Mokhlesi B, Hovda MD, Vekhter B, Arora VM, Chung F, Meltzer DO. Sleep-disordered breathing and postoperative outcomes after elective surgery: analysis of the nationwide inpatient sample. Chest. 2013;144:903-14.

25 Roesslein M, Chung F. Obstructive sleep apnoea in adults: peri-operative considerations: a narrative review. Eur J Anaesthesiol. 2018 Apr;35(4):245-55.

26 Chung F, Liao P, Elsaid H, Shapiro CM, Kang W. Factors associated with postoperative exacerbation of sleep-disordered breathing. Anesthesiology. 2014;120:299-311.

27 Buchwald H, Avidor Y, Braunwald E, Jensen MD, Pories W, Fahrbach K, et al. Bariatric surgery: a systematic review and meta-analysis. JAMA. 2004 Oct 13;292(14):1724-37.

28 Henriksen NA, Bisgaard T, Helgstrand F; Danish Hernia Database. Smoking and obesity are associated with increased readmission after elective repair of small primary ventral hernias: a nationwide database study. Surgery. 2020 Sep;168(3):527-31.

29 Abdel Jalil R, Al-Najjar H, Abou Chaar MK, Al-Masri M, Daoud F, Al-Ebous A, et al. The impact of a perioperative pulmonary care bundle implementation on postoperative outcomes in 1,665 surgical cancer patients: experience from a tertiary referral cancer center in Jordan. Patient Saf Surg. 2021 Jan 6;15(1):5.

30 Kaufman EJ, Hatchimonji JS, Ma LW, Passman J, Holena DN. Complications and failure to rescue after abdominal surgery for trauma in obese patients. J Surg Res. 2020 Jul;251: 211-9.

31 Mathur AK, Ghaferi AA, Sell K, Sonnenday CJ, Englesbe MJ, Welling TH. Influence of body mass index on complications and oncologic outcomes following hepatectomy for malignancy. J Gastrointest Surg. 2010 May; 14(5):849-57.

32 Daigle CR, Brethauer SA, Tu C, Petrick AT, Morton JM, Schauer PR, et al. Which postoperative complications matter most after bariatric surgery? Prioritizing quality improvement efforts to improve national outcomes. Surg Obes Relat Dis. 2018 May;14(5):652-7.

33 Teh SH, Nagorney DM, Stevens SR, Offord KP, Therneau TM, Plevak DJ, et al. Risk factors for mortality after surgery in patients with cirrhosis. Gastroenterology. 2007;132: 1261-9. 
34 Lee KC, Chung KC, Chen HH, Cheng KC, $\mathrm{Wu} \mathrm{KL}, \mathrm{Lu} \mathrm{CC}$. Short-term postoperative outcomes of colorectal cancer among patients with chronic liver disease: a national population-based study. BMJ Open. 2018 Jul 17;8(7): e020511.

35 Clark JM. The epidemiology of nonalcoholic fatty liver disease in adults. J Clin Gastroenterol. 2006;40(Suppl 1):S5-10.

36 Lassailly G, Caiazzo R, Buob D, Pigeyre M, Verkindt H, Labreuche J, et al. Bariatric surgery reduces features of nonalcoholic steatohepatitis in morbidly obese patients. Gastroenterology. 2015 Aug;149(2):379-6.

37 Carbajo MA, Castro MJ, Kleinfinger S, Gómez-Arenas S, Ortiz-Solórzano J, Wellman R, et al. Effects of a balanced energy and high protein formula diet (vegestart complet ${ }^{\circledR}$ ) versus low-calorie regular diet in morbid obese patients prior to bariatric surgery (laparoscopic single anastomosis gastric bypass): a prospective, double-blind randomized study. Nutr Hosp. 2010 Nov;25(6):939-48.

38 Chakravartty S, Vivian G, Mullholland N, Shaikh H, McGrath J, Sidhu PS, et al. Preoperative liver shrinking diet for bariatric surgery may impact wound healing: a randomized controlled trial. Surg Obes Relat Dis. 2019 Jan;15(1):117-25.

39 Neeff H, Mariaskin D, Spangenberg HC, Hopt UT, Makowiec F. Perioperative mortality after non-hepatic general surgery in patients with liver cirrhosis: an analysis of 138 operations in the 2000s using Child and MELD scores. J Gastrointest Surg. 2011 Jan; 15(1):1-11.

40 Sharma AM, Kushner RF. A proposed clinical staging system for obesity. Int J Obes. 2009;33: 289-95.

41 Gill RS, Karmali S, Sharma AM. The potential role of the edmonton obesity staging system in determining indications for bariatric surgery. Obes Surg. 2011 Dec;21(12):1947-9.

42 Bell S, Kong JC, Carne PWG, Chin M, Simpson P, Farmer C, et al. Oncological safety of laparoscopic versus open colorectal cancer surgery in obesity: a systematic review and meta-analysis. ANZ J Surg. 2019 Dec;89(12): 1549-55.

43 Yang T, Wei M, He Y, Deng X, Wang Z. Impact of visceral obesity on outcomes of laparoscopic colorectal surgery: a meta-analysis. ANZ J Surg. 2015 Jul;85(7-8):507-13.

44 van der Pas MH, Haglind E, Cuesta MA, Fürst A, Lacy AM, Hop WC, et al. Laparoscopic versus open surgery for rectal cancer (COLOR II): short-term outcomes of a randomised, phase 3 trial. Lancet Oncol. 2013;14(3):210-8.

45 Wee IJY, Kuo LJ, Ngu JC. The impact of robotic colorectal surgery in obese patients: a systematic review, meta-analysis, and metaregression. Surg Endosc. 2019 Nov;33(11): 3558-66.

46 Nguyen NT, Goldman C, Rosenquist CJ, Arango A, Cole CJ, Lee SJ, et al. Laparoscopic versus open gastric bypass: a randomized study of outcomes, quality of life, and costs. Ann Surg. 2001;234:279-91.

47 Mengardo V, Pucetti F, Mc Cormack O, Chaudry A, Allum WH. The impact of obesity on esophagectomy: a meta-analysis. Dis Esophagus. 2018 Jun 1;31(6):31.
48 Kayani B, Okabayashi K, Ashrafian H, Harling L, Rao C, Darzi A, et al. Does obesity affect outcomes in patients undergoing esophagectomy for cancer? A meta-analysis. World J Surg. 2012 Aug;36(8):1785-95.

49 Salem AI, Thau MR, Strom TJ, Abbott AM, Saeed N, Almhanna K, et al. Effect of body mass index on operative outcome after robotic-assisted Ivor-Lewis esophagectomy: retrospective analysis of 129 cases at a single highvolume tertiary care center. Dis Esophagus. 2017 Jan 1;30(1):1-7.

50 Sachdeva UM, Axtell AL, Kroese TE, Chang DC, Morse CR. Impact of obesity on treatment approach for resectable esophageal cancer. Ann Thorac Surg. 2020 Dec 17;S00034975(20):32129-9.

51 Mitzman B, Schipper PH, Edwards MA, Kim $\mathrm{S}$, Ferguson MK. Complications after esophagectomy are associated with extremes of body mass index. Ann Thorac Surg. 2018 Oct; 106(4):973-80.

52 Sun L, Zhao B, Huang Y, Lu H, Luo R, Huang B. Feasibility of laparoscopy gastrectomy for gastric cancer in the patients with high body mass index: a systematic review and meta-analysis. Asian J Surg. 2020 Jan; 43(1):69-77.

53 Abdelrahman T, Latif A, Chan DS, Jones H, Farag M, Lewis WG, et al. Outcomes after laparoscopic anti-reflux surgery related to obesity: a systematic review and meta-analysis. Int J Surg. 2018 Mar;51:76-82.

54 McIntyre C, Johnston A, Foley D, Lawler J, Bucholc M, Flanagan L, et al. Readmission to hospital following laparoscopic cholecystectomy: a meta-analysis. Anaesthesiol Intensive Ther. 2020;52(1):47-55.

55 Enami Y, Aoki T, Tomioka K, Hakozaki T, Hirai $\mathrm{T}$, Shibata $\mathrm{H}$, et al. Obesity is not a risk factor for either mortality or complications after laparoscopic cholecystectomy for cholecystitis. Sci Rep. 2021 Jan 27;11(1):2384.

56 Tracy BM, Paterson CW, Torres DM, Young K, Hochman BR, Zielinski MD, et al. EAST retained common bile duct stones study group. risk factors for complications after cholecystectomy for common bile duct stones: an east multicenter study. Surgery. $2020 \mathrm{Jul} ; 168(1): 62-6$.

57 Shamali A, Shelat V, Jaber B, Wardak A, Ahmed M, Fontana M, et al. Impact of obesity on short and long term results following a pancreatico-duodenectomy. Int J Surg. 2017 Jun;42:191-6.

58 Ramsey AM, Martin RC. Body mass index and outcomes from pancreatic resection: a review and meta-analysis. J Gastrointest Surg. 2011 Sep;15(9):1633-42

59 Saab S, Lalezari D, Pruthi P, Alper T, Tong MJ. The impact of obesity on patient survival in liver transplant recipients: a meta-analysis. Liver Int. 2015 Jan;35(1):164-70.

60 Skulsky SL, Dang JT, Battiston A, Switzer NJ, Birch DW, Sharma AM, et al. Higher edmonton obesity staging system scores are associated with complications following laparoscopic Roux-en-Y gastric bypass. Surg Endosc. 2020 Jul;34(7):3102-9.

61 Benoist S, Panis Y, Alves A, Valleur P. Impact of obesity on surgical outcomes after colorectal resection. Am J Surg. 2000;179:275-81.
62 Woodham BL, Cox MR, Eslick GD. Evidence to support the use of laparoscopic over open appendicectomy for obese individuals: a meta-analysis. Surg Endosc. 2012;26:2566-70.

63 Flum DR, Flum DR, Belle SH, King WC, Wahed AS, Berk P, et al. Perioperative safety in the longitudinal assessment of bariatric surgery. N Engl J Med. 2009 Jul 30;361(5):44554.

64 Danwang C, Agbor VN, Bigna JJ. Obesity and postoperative outcomes of the patients with laparoscopic adrenalectomy: a systematic review and meta-analysis. BMC Surg. 2020 Aug 31;20(1):194.

65 Weber KT, Chung PJ, La Gamma N, Procaccino JA, Alfonso AE, Coppa G, et al. Effect of body mass index on outcomes after surgery for perforated diverticulitis. J Surg Res. 2020 Mar;247:220-6.

66 Makino T, Trencheva K, Shukla PJ, Rubino F, Zhuo C, Pavoor RS, et al. The influence of obesity on short- and long-term outcomes after laparoscopic surgery for colon cancer: a case-matched study of 152 patients. Surgery. 2014 Sep;156(3):661-8.

67 Leroy J, Ananian P, Rubino F, Claudon B, Mutter D, Marescaux J. The impact of obesity on technical feasibility and postoperative outcomes of laparoscopic left colectomy. Ann Surg. 2005 Jan;241(1):69-76.

68 Harr JN, Luka S, Kankaria A, Juo YY, Agarwal S, Obias V. Robotic-assisted colorectal surgery in obese patients: a case-matched series. Surg Endosc. 2017 Jul;31(7):2813-9.

69 Markar SR, Ni M, Gisbertz SS, van der Werf L, Straatman J, van der Peet D, et al. Dutch upper GI cancer audit and time study group. implementation of minimally invasive esophagectomy from a randomized controlled trial setting to national practice. J Clin Oncol. 2020 Jul 1;38(19):2130-9.

70 Kohn GP, Galanko JA, Overby DW, Farrell TM. High case volumes and surgical fellowships are associated with improved outcomes for bariatric surgery patients: a justification of current credentialing initiatives for practice and training. J Am Coll Surg. 2010 Jun;210(6): 909-18.

71 Yamashita S, Nishi M, Ikemoto T, Yoshikawa K, Higashijima J, Tokunaga T, et al. Clinical analysis of postoperative venous thromboembolism in Japanese patients after colorectal cancer surgery. Surg Today. 2021 Jun;51(6): 1022-27.

72 Fleming F, Gaertner W, Ternent CA, Finlayson E, Herzig D, Paquette IM, et al. The American Society of Colon and Rectal Surgeons clinical practice guideline for the prevention of venous thromboembolic disease in colorectal surgery. Dis Colon Rectum. 2018; 61(1):14-20.

73 Wang P, Li Y, Sun H, Liu S, Zhang R, Liu X, et al. Predictive value of body mass index for short-term outcomes of patients with esophageal cancer after esophagectomy: a metaanalysis. Ann Surg Oncol. 2019 Jul;26(7): 2090-103. 
74 Steib A, Degirmenci SE, Junke E, Asehnoune $\mathrm{K}$, Figier M, Pericard C, et al. Once versus twice daily injection of enoxaparin for thromboprophylaxis in bariatric surgery: effects on antifactor Xa activity and procoagulant microparticles. A randomized controlled study. Surg Obes Relat Dis. 2016 Mar;12(3):613-21.

75 Hamadi R, Marlow CF, Nassereddine S, Taher A, Finianos A. Bariatric venous thromboembolism prophylaxis: an update on the literature. Expert Rev Hematol. 2019;12(9): 763-71.

76 Chiappetta S, Stier C, Weiner RA. members of StuDoQ|MBE of Deutsche Gesellschaft für Allgemein- und Viszeralchirurgie/StuDoQ.
The edmonton obesity staging system predicts perioperative complications and procedure choice in obesity and metabolic surgerya german nationwide register-based cohort study (StuDoQ|MBE). Obes Surg. 2019 Dec; 29(12):3791-9.

77 Lee HJ, Hyung WJ, Yang HK, Han SU, Park YK, An JY, et al. Short-term outcomes of a multicenter randomized controlled trial comparing laparoscopic distal gastrectomy with D2 lymphadenectomy to open distal gastrectomy for locally advanced gastric cancer (KLASS-02RCT). Ann Surg. 2019;270(6):983-91.

78 Jayne DG, Thorpe HC, Copeland J, Quirke P, Brown JM, Guillou PJ. Five-year follow-up of the medical research council clasicc trial of laparoscopically assisted versus open surgery for colorectal cancer. Br J Surg. 2010;97(11): 1638-45.

79 Hong L, Zhang H, Zhao Q, Han Y, Yang J, Brain L, Relation of excess body weight and survival in patients with esophageal adenocarcinoma: a meta-analysis diseases of the Esophagus. Dis Esophagus. 2013;26: 623-7.

80 Fung A, Trabulsi N, Morris M, Garfinkle R, Saleem A, Wexner SD, et al. Laparoscopic colorectal cancer resections in the obese: a systematic review. Surg Endosc. 2017 May; 31(5):2072-88 